\title{
NMDA Receptor Dependence of Kindling and Mossy Fiber Sprouting: Evidence that the NMDA Receptor Regulates Patterning of Hippocampal Circuits in the Adult Brain
}

\author{
T. Sutula, ${ }^{1,2}$ J. Koch, ${ }^{1}$ G. Golarai, ${ }^{1,2}$ Y. Watanabe, ${ }^{3,4,5}$ and J. O. McNamara ${ }^{3,4,5}$ \\ ${ }^{1}$ Departments of Neurology and Anatomy, and the ${ }^{2}$ Neuroscience Training Program, University of Wisconsin, Madison, \\ Wisconsin 53292, and Departments of ${ }^{3}$ Medicine (Neurology) and ${ }^{4}$ Neurobiology and Pharmacology, and 5 the Epilepsy \\ Research Laboratory, Veterans Affairs Medical Center, Duke University, Durham, North Carolina 27705
}

\begin{abstract}
The NMDA receptor plays an important role in patterning neural connectivity in the developing brain. In the adult brain, repeated kindling stimulation of limbic pathways increases the NMDAdependent component of synaptic transmission in granule cells of the dentate gyrus (DG) and also induces sprouting of the mossy fiber axons of granule cells that reorganizes synaptic connections in the DG. Because the NMDA antagonist MK801 impedes the progression of kindling, it was of interest to determine whether MK801 also modified mossy fiber sprouting. Low doses of MK801, which had no antiseizure effect, impaired the progression of kindling and development of mossy fiber sprouting during the initial and also more advanced stages of
\end{abstract}

kindling. These observations demonstrate that the NMDA receptor is a component of a molecular pathway that influences the progression of kindling and mossy fiber sprouting and suggest that NMDA-dependent gene expression may play a role in the development of long-term structural and functional alterations induced by seizures in hippocampal circuitry. The NMDA receptor appears to play a continuing role in modifying the organization and patterns of connectivity in hippocampal circuits of the adult brain.

Key words: NMDA; kindling; sprouting; hippocampus; plasticity; receptors; MK801; dentate gyrus; seizures epilepsy
Kindling is a model of brain plasticity in which repeated activation of neural pathways induces increasing susceptibility to evoked seizures and eventual progression to spontaneous seizures (Goddard et al., 1969). There has been considerable interest in understanding the molecular and cellular processes that underlie the permanent alteration in brain function induced by kindling, which is a model of temporal lobe epilepsy (McNamara, 1994) and memory dysfunction (Sutula et al., 1995). Because the dentate gyrus (DG) plays a role in the development of kindling, there has been particular interest in the molecular and cellular alterations induced by kindling in this structure (Frush et al., 1986; Sutula et al., 1986).

The initial electrographic seizures evoked by kindling induce a long-lasting increase in excitatory synaptic transmission (Sutula and Steward, 1986), which is at least partly mediated by the NMDA subfamily of glutamate-gated ion channels in granule cells of the DG (Mody and Heinemann, 1987; Mody et al., 1988). This initial physiological alteration is accompanied by a complex, evolving sequence of gene expression, which includes transient increases in expression of transcription factors (Dragunow and Robertson, 1987; Shin et al., 1990; Morgan and Curran, 1991; Labiner et al., 1993; Hope et al., 1994; Hosford et al., 1995) and more slowly evolving changes in neurotrophins (Gall and Isackson, 1989; Ernfors et al., 1991; Gall, 1993; Lindvall et al., 1994;

Received May 14, 1996; revised Aug. 30, 1996; accepted Sept. 4, 1996

This work was supported by National Institute of Neurological Diseases and Stroke (NINDS) Grant 25020 (T.S.), the Klingenstein Fund (T.S.), and NINDS Grant 32334 (J.O.M.). We thank Dr. Paul Anderson of Merck, Sharp \& Dohme, who provided MK801, and Mike Lynch, who assisted in statistical analysis.

Correspondence should be addressed to Dr. T. Sutula, Department of Neurology H6/570, University of Wisconsin, Madison, WI 53792.

Copyright (C) 1996 Society for Neuroscience $0270-6474 / 96 / 167398-09 \$ 05.00 / 0$
Khrestchatisky et al., 1995), neurotrophic factor receptors (Bengzon et al., 1993; Bugra et al., 1994), and axonal growth-associated proteins such as GAP-43 (Bendotti et al., 1993; Meberg, 1993).

The initial seizure-induced alterations in NMDA-dependent synaptic transmission and gene expression are followed by more slowly evolving cellular alterations that include sprouting of the mossy fiber pathway in the DG (Sutula et al., 1988; Cavazos et al., 1991). Sprouting of the mossy fiber pathway establishes new synaptic connections in the supragranular region of the DG (Sutula et al., 1988; Cavazos et al., 1991), where mossy fiber terminals are not normally found (Claiborne et al., 1986). There is considerable uncertainty about the overall effects of sprouting on excitability of hippocampal pathways (Tauck and Nadler, 1985; Cronin et al., 1992; Sloviter, 1992; Buhl et al., 1996), but recent studies have provided evidence that sprouted mossy fibers modify the sequence of synaptic events in the DG (Golarai and Sutula, 1996) and may increase recurrent excitation (Waurin and Dudek, 1996). Mossy fiber sprouting, which progresses with repeated kindled seizures (Cavazos et al., 1991) and is observed in a variety of experimental models of epilepsy (Tauck and Nadler, 1985; Represa et al., 1989a; Stanfield, 1989; Golarai et al., 1992; Qiao and Noebels, 1993), is also a feature of human temporal lobe epilepsy (de Lanerolle et al., 1989; Represa et al., 1989b; Sutula et al., 1989; Houser et al., 1990).

There is relatively limited understanding about how the initial seizure-induced changes in synaptic transmission and gene expression are translated into long-term structural and functional alterations that are characteristic of the kindled state. Although the NMDA receptor plays an important role in shaping the connectivity and organization of circuitry in development (Cline and Constantine-Paton, 1990; Shatz, 1990), it is not clear whether the NMDA receptor continues to directly influence the organization 
and connectivity of neural circuitry in the adult brain. Because MK801, an uncompetitive blocker of the NMDA receptor-gated channels (Lodge and Johnson, 1990), impedes the progression of kindling at doses that have minimal or no antiseizure effect (Callahan and Schwark, 1980; Bowyer et al., 1983; McNamara et al., 1988; Sato et al., 1988; Gilbert and Mack, 1990; Giorgi et al., 1991), it was of interest to investigate whether the NMDA receptors play a role in translating the initial effects of seizures into long-term structural and functional alterations of neurons in the DG. The aim of this study was to analyze the effects of MK801 on the correlation between evoked seizures, progression of kindling, and mossy fiber sprouting in response to repeated electrical stimulation of the perforant path. A preliminary report has appeared in abstract form (Koch et al., 1994).

\section{MATERIALS AND METHODS}

Surgical procedures. Sprague Dawley male rats (250-350 gm) were anesthetized with pentobarbital $(60 \mathrm{mg} / \mathrm{kg}$, i.p.) and were stereotaxically implanted with an insulated stainless steel bipolar electrode in the left perforant path for stimulation and recording. The electrode was implanted in the region of the angular bundle $(8.1 \mathrm{~mm}$ posterior, $4.4 \mathrm{~mm}$ lateral, $3.5 \mathrm{~mm}$ ventral from bregma) and was fixed to the skull with acrylic. Electrode placement was confirmed by histological analysis at the conclusion of the experiments.

Administration of MK801. After a recovery period of 2 weeks, rats were randomly assigned to groups that received either MK801 [(+)-5methyl-10,11-dihydroxy-5H-dibenzo-(a,d)-cyclohepten-5,10-imine maleate] at a dose of $0.5 \mathrm{mg} / \mathrm{kg}$ or an equivalent volume of $0.9 \%(\mathrm{w} / \mathrm{v})$ aqueous $\mathrm{NaCl}$ administered subcutaneously 30 min before kindling stimulation. This dose of MK801 was chosen, because previous studies have demonstrated that a dose of $0.5 \mathrm{mg} / \mathrm{kg}$ impedes development of kindling but has minimal anticonvulsant activity against fully developed kindled seizures (McNamara et al., 1988; Sato et al., 1988). MK801 was injected $30 \mathrm{~min}$ before kindling stimulation, because peak effects of the drug were apparent at this interval after subcutaneous administration, as indicated by impairments including reduced spontaneous motor activity and postural instability (Löscher and Hönack, 1991).

Kindling procedures and analysis. The unrestrained awake animals from the MK801 and control groups received once-daily kindling stimulation ( $5 \mathrm{~d}$ per week) with a $1 \mathrm{sec}$ train of $62 \mathrm{~Hz}$ biphasic constant current 1.0 msec square wave pulses, according to standard procedures. The electroencephalogram and afterdischarge (AD) were recorded from the bipolar electrode in the perforant path, which was electronically switched to the stimulator for for delivery of kindling stimulation. On the first day of stimulation, each rat received a stimulus train of $500 \mu \mathrm{A}$. If an $\mathrm{AD}$ was evoked, this intensity was used in subsequent stimulations. If no $\mathrm{AD}$ was evoked, the stimulation intensity was increased on subsequent days in a sequence of $500,700,900,1000,1100,1200,1300$, and $1400 \mu \mathrm{A}$ until an $\mathrm{AD}$ was evoked. The intensity that initially evoked $\mathrm{AD}$ was used for subsequent stimulations. If $1400 \mu \mathrm{A}$ failed to evoke $\mathrm{AD}$, stimulation was continued on subsequent days at $1400 \mu \mathrm{A}$. If $\mathrm{AD}$ was evoked by three consecutive stimulations at a given intensity, the stimulation intensity was then decreased in $50 \mu \mathrm{A}$ decrements. At stimulation intensities at or below $500 \mu \mathrm{A}$, the intensity was decreased in $30 \mu$ decrements. Similar stimulation procedures have been used in previous studies to deliver stimulation at the lowest intensity required to evoke an AD (Sutula and Steward, 1986; Cavazos et al., 1991).

The evoked behavioral seizures were classified according to standard criteria (Racine, 1972; Sutula and Steward, 1986). The mean AD thresholds for the MK801 and the control groups injected with saline were calculated as the average of the initial stimulation intensity that evoked an $\mathrm{AD}$. Mean $\mathrm{AD}$ duration was recorded as the time from completion of the stimulus to the end of the primary $\mathrm{AD}$, which was defined by the cessation of the initial train of repetitive spike or spike-wave discharges. Secondary ADs, which are spontaneous spike or spike-wave discharges after the period of baseline suppression after the initial primary $\mathrm{AD}$, were not included in the calculation of $\mathrm{AD}$ duration. The differences in mean $\mathrm{AD}$ thresholds and durations were analyzed for statistical significance by an ANOVA, and individual comparisons were assessed by the Student's $t$ test.

Histological procedures. Synaptic reorganization of the mossy fiber pathway was evaluated by the Timm method, a histochemical technique that labels the synaptic terminals of the mossy fibers because of their high content of $\mathrm{Zn}^{+2}$ (Danscher et al., 1985). At least $18 \mathrm{hr}$ after the last seizure, the kindled rats were perfused with $400 \mathrm{ml}$ of $0.4 \%$ (w/v) $\mathrm{Na}_{2} \mathrm{~S}$ in deionized $\mathrm{H}_{2} \mathrm{O}$, followed by fixation with $400 \mathrm{ml}$ of an aqueous solution of $1 \%(\mathrm{w} / \mathrm{v})$ paraformaldehyde and $1.25 \%(\mathrm{w} / \mathrm{v})$ glutaraldehyde. The brains were removed, immersed overnight in the fixative solution saturated with sucrose, rapidly frozen in dry ice, and cut into horizontal $40 \mu \mathrm{m}$ sections with a freezing microtome. The sections were mounted on gelatin-coated slides and stained by the Timm method and cresyl violet, as described previously (Cavazos et al., 1991).

Scoring methods for Timm histochemistry. The extent of mossy fiber sprouting and synaptic reorganization in kindled and normal rats was analyzed independently by three observers who were unaware of the identity of each brain section, using a previously published, standardized scoring procedure (Cavazos et al., 1991, 1992). Mossy fiber synaptic reorganization was evaluated by rating the distribution of Timm granules, which correspond to synaptic terminals of the mossy fiber pathway, at a standard location in the supragranular layer of the left and right dorsal (septal) DG (Fig. 1). The theoretical basis, procedures, and statistical analysis for the scoring method are available in previous publications (Cavazos et al., 1991, 1992).

The distribution of Timm granules in the supragranular region was rated on a scale of 0 to 5 according to the following criteria: 0 , no granules between tips and crest of the DG; 1 , sparse granules in the supragranular region in a patchy distribution between the tips and crest of the DG; 2 , more numerous granules in the supragranular region in a continuous pattern between the tips and crest of the DG; 3, prominent granules in the supragranular region in a continuous pattern between tips and crest, with occasional patches of confluent granules between tips and crest of the DG; 4, prominent granules in the supragranular region that form a confluent dense laminar band between tips and crest; 5, a confluent dense laminar band of granules in the supragranular region that extends into the inner molecular layer.

A Timm score for the standard section of the left and right DG was determined independently by each examiner. Because there were no differences between left and right scores, a Timm score for each rat was calculated by averaging the independently derived scores from the standard sections of the left and right DG of each rat. Mean Timm scores for the MK801 and control groups were analyzed for statistical significance by a one-way ANOVA and by the Student's $t$ test.

\section{RESULTS}

MK801 was administered during the initial and advanced stages of kindling to specifically assess the effect of NMDA blockade at particular stages of the kindling process. MK801 was administered during the initiation of kindling (0-17 ADs group, $n=7)$, during a later stage of kindling induction (10 ADs to 1 class V seizure group, $n=9)$, and in fully kindled rats (1-10 class V Seizure group, $n=9)$. Control groups were injected with saline before each kindling stimulation and received kindling stimulation until 1 class V seizure was evoked $(n=9)$ or until 10 class V seizures were evoked $(n=8)$.

\section{Effects of MK801 on AD threshold}

The AD is an electrographic seizure reflecting synchronous neural activity. Administration of MK801 $0.5 \mathrm{mg} / \mathrm{kg} 30 \mathrm{~min}$ before the initial kindling stimulation increased the mean initial stimulus strength required to evoke $\mathrm{AD}$ compared with the saline injected control group $(1007 \pm 133 \mu \mathrm{A}$ vs $561 \pm 42.3 \mu \mathrm{A}, p=0.0003)$ but did not prevent the development of AD (Table 1).

In agreement with previous studies (Goddard et al., 1969; Racine et al., 1972), repeated kindling stimulation produced a gradual, progressive decrease in the stimulus strength required to evoke an $\mathrm{AD}$ in the untreated control groups $(p=0.0001$, ANOVA) (see Table 1). There was also a trend toward gradual decrease in the group pretreated with MK801 during the initial stages of kindling from 0 to 17 ADs, but the stimulus strength required to evoke the 17 th $\mathrm{AD}$ in this group remained significantly greater than the initial $\mathrm{AD}$ thresholds of the other control 


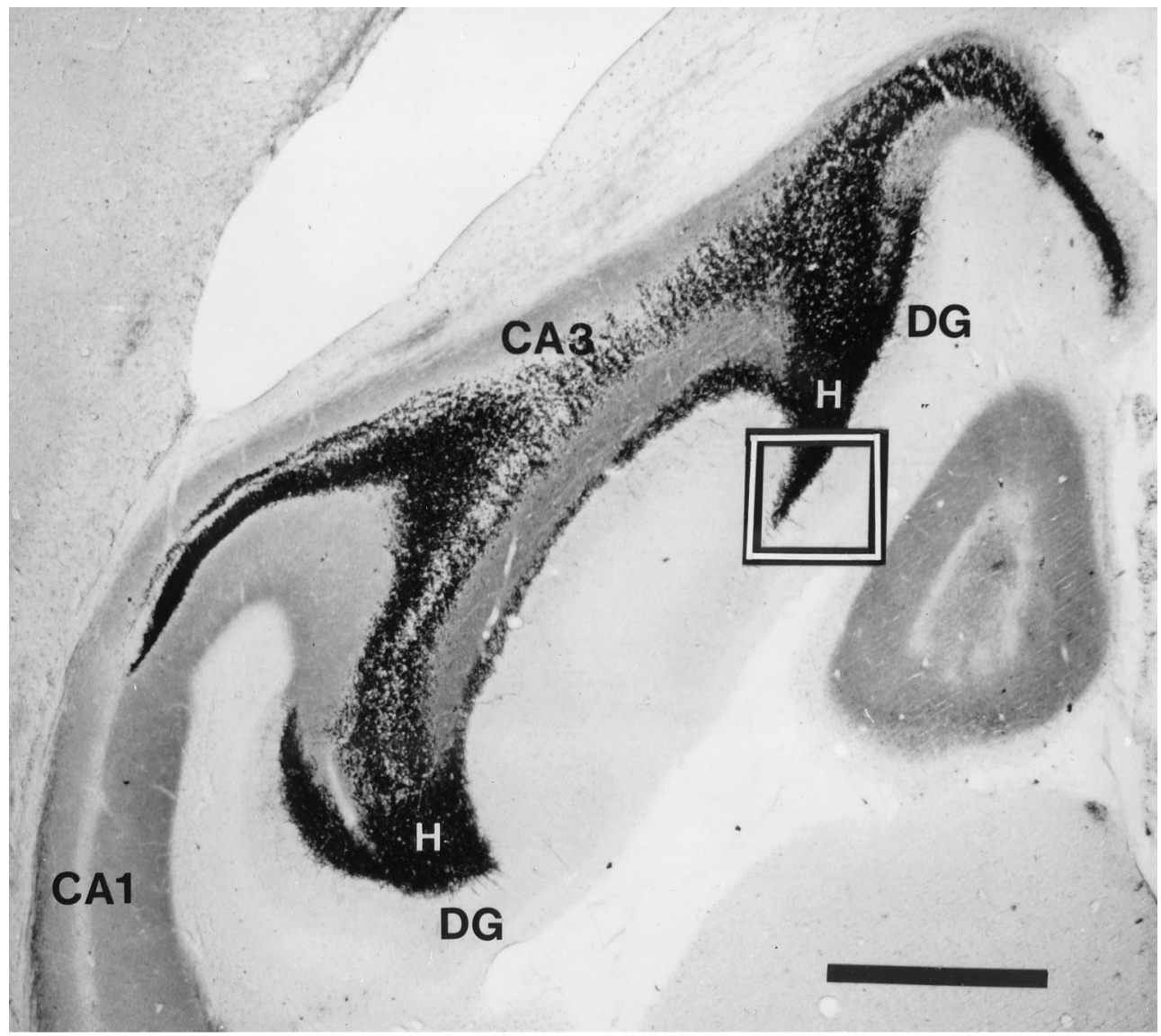

Figure 1. Horizontal section of the hippocampus and DG in a normal rat stained by the Timm method demonstrates the normal terminal field of the mossy fiber axons arising from granule cells in the DG. Dense areas of dark staining areas in the DG and CA3 fields are locations of synapses of mossy fiber axons, which stain darkly because of their high content of $\mathrm{Zn}$. The area outlined by the box is the standard location in the DG that was evaluated by scoring methods for Timm histochemistry. $H$, Hilus; $D G$, dentate gyrus. Scale bar, $1000 \mu \mathrm{m}$.

compared with untreated control groups ( $p=0.0001$, ANOVA) (see Fig. 2, Table 2). This effect was observed in the group pretreated with MK801 during the stage of $0-17$ ADs and also in the groups pretreated after the 10th $\mathrm{AD}$ and after the first class $\mathrm{V}$ seizure. MK801 pretreatment prolonged AD duration during the initial and more advanced stages of kindling, but there were no other consistent differences observed in the ADs of the treated and control groups.

\section{Effects of MK801 on the progression of kindling}

The progression of kindling in response to repeated stimulation can be assessed by the number of ADs required to evoke stereotypical behaviors that define the behavioral stages. The number of ADs required to evoke the first generalized tonic-clonic (class V) seizure is frequently used as a measure of the rate of progression 1990; Gilbert, 1991; Labiner et al., 1993), pretreatment MK801 significantly prolonged the mean cumulative AD duration

Table 1. Effects of MK801 and kindling on afterdischarge threshold (microamps \pm SEM)

\begin{tabular}{|c|c|c|c|c|c|c|c|}
\hline & 1st $\mathrm{AD}^{*}$ & 10th AD & 11th AD & 17th AD & 1st class $\mathrm{V}$ & 2nd class $V$ & 10th class V \\
\hline $\begin{array}{l}\text { Controls } \\
1 \text { class V }\end{array}$ & $561 \pm 42$ & $495 \pm 39$ & $491 \pm 40$ & $467 \pm 79$ & $467 \pm 47$ & - & - \\
\hline $\begin{array}{l}\text { Controls } \\
10 \text { class V }\end{array}$ & $562 \pm 73$ & $490 \pm 60$ & $484 \pm 61$ & $437 \pm 61$ & $435 \pm 55$ & $417 \pm 57$ & $314 \pm 52$ \\
\hline $\begin{array}{l}\text { MK801 } \\
0-17 \text { ADs }\end{array}$ & $1007 \pm 133^{* *}$ & $900 \pm 102$ & $885 \pm 106$ & $785 \pm 100$ & - & - & - \\
\hline $\begin{array}{l}\text { MK801 } \\
\quad 10 \text { ADs-1 class V }\end{array}$ & $572 \pm 49$ & $517 \pm 44$ & $505 \pm 49$ & $439 \pm 42$ & $364 \pm 35$ & - & - \\
\hline $\begin{array}{l}\text { MK801 } \\
\quad 1-10 \text { class V }\end{array}$ & $594 \pm 53$ & $575 \pm 67$ & $566 \pm 66$ & $455 \pm 43$ & $471 \pm 49$ & $453 \pm 44$ & $282 \pm 33$ \\
\hline
\end{tabular}

*Versus final AD thresholds, $F=16.4, p=0.0001$, ANOVA; **versus initial AD thresholds, $F=6.5, p=0.0004$, ANOVA. 

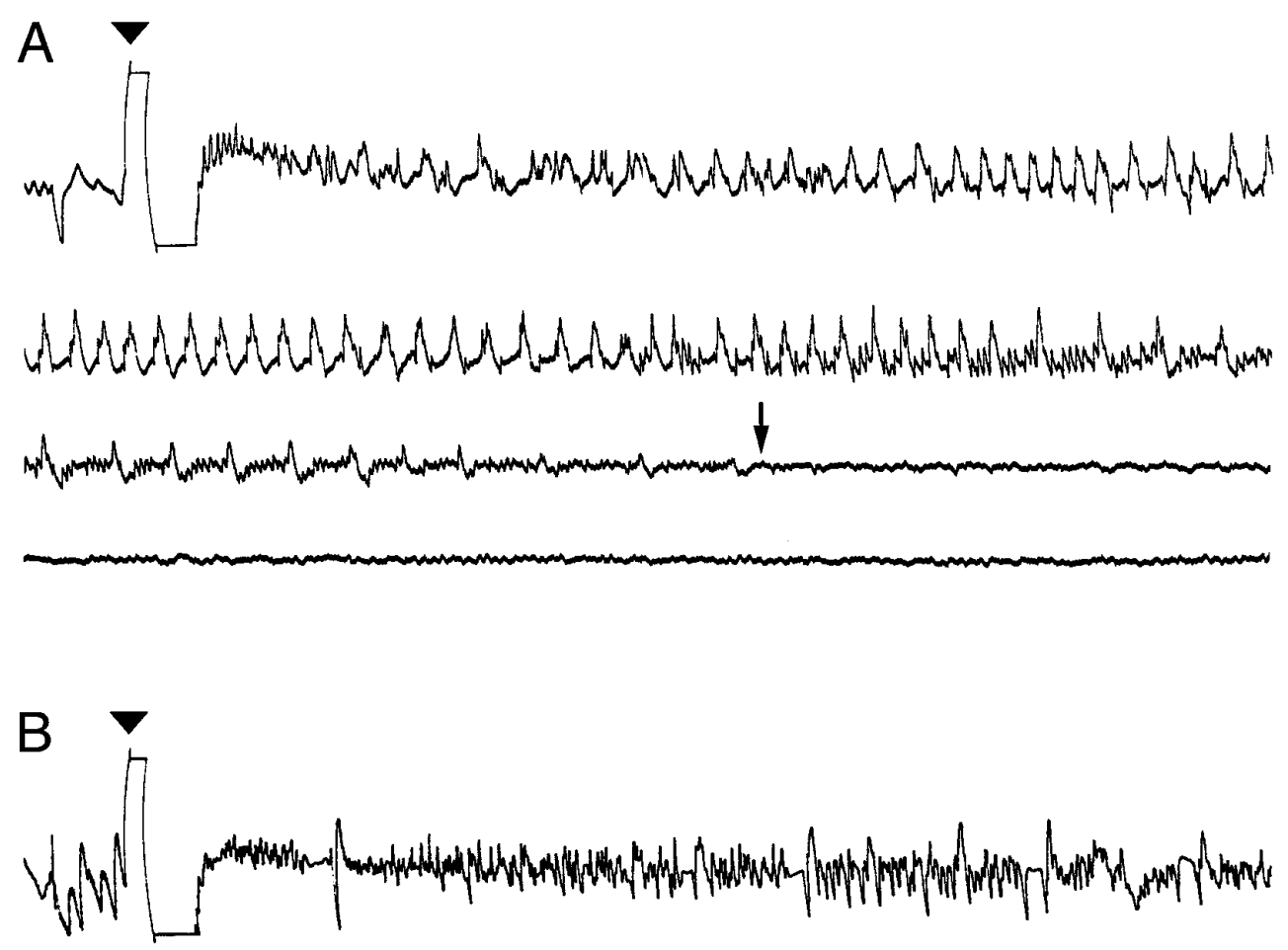

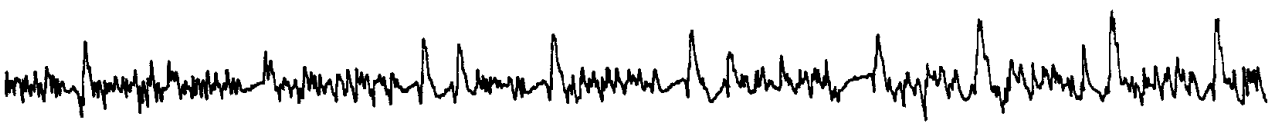
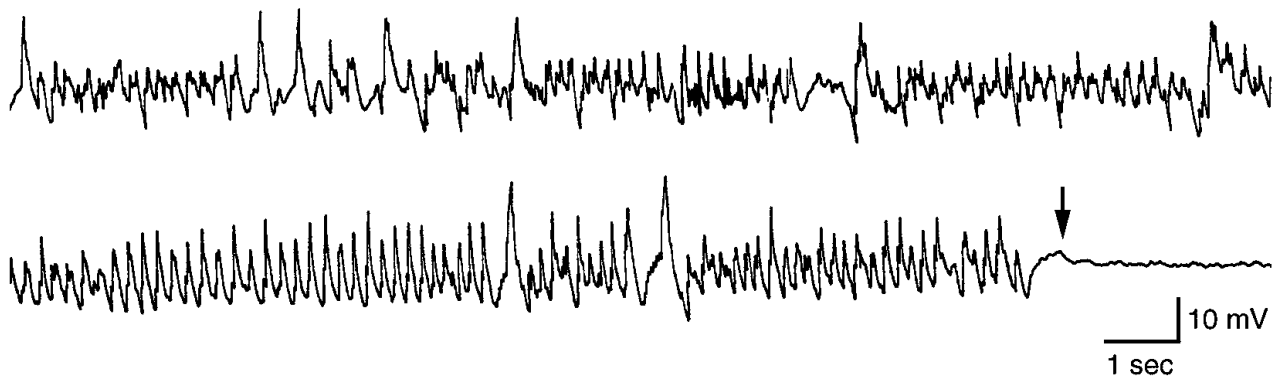

Figure 2. Examples of continuous recordings from a depth electrode in the perforant path of rats that received injections of either saline $(A)$ saline or MK801 (B) $30 \mathrm{~min}$ before stimulation of the perforant path with a $1 \mathrm{sec}$ train of $62 \mathrm{~Hz}$, 1 msec biphasic constant current pulses (arrowhead). $A$, In a saline-injected rat, a perforant path stimulus of $500 \mu \mathrm{A}$ evoked an $\mathrm{AD}$ that began with a brief run of high-frequency spike discharges that was immediately followed by repetitive irregular spike and spike-wave discharges that gradually decreased in frequency, which were followed by lower-amplitude featureless activity. The arrow indicates the end of the AD, which had a duration of 43 sec. $B$, In a rat treated with MK801 30 min before perforant path stimulation, a $1400 \mu \mathrm{A}$ stimulus train evoked an AD that also began with brief high-frequency discharges that evolved into repetitive spike and irregular spike-wave discharges. The arrow at the onset of low-amplitude featureless activity indicates the end of the AD, which had a duration of $64 \mathrm{sec}$. Calibration bars are for both $A$ and $B$. Rats pretreated with MK801 had a higher initial $\mathrm{AD}$ threshold and experienced ADs of longer duration than salineinjected controls (see text and Table 2 for details). of kindling, because this behavioral seizure is particularly easy to identify, and permanent susceptibility to evoked kindled seizures is acquired by this stage.

In the group pretreated with MK801 beginning at the initial stimulation, there was an impairment in the development of class $\mathrm{V}$ kindled seizures in response to perforant path stimulation. After 17 stimulations that evoked AD, this pretreated group only reached behavioral class III. In contrast, the saline-injected control group experienced the first evoked class $\mathrm{V}$ seizure after a mean of $17.2 \pm 1.8$ ADs. Although the group pretreated with MK801 experienced nearly identical numbers of evoked ADs and had a longer cumulative $\mathrm{AD}$ duration than the saline-injected control group (Table 2) $(p<0.017)$, pretreatment with MK801 impaired the progression of kindling to the stage of class $\mathrm{V}$ seizures.

MK801 also impaired the progression of kindling when pretreatment was initiated after the 10th $\mathrm{AD}$ and was continued until the first evoked class V seizure. In this group, $24.2 \pm 1.7$ ADs were required to achieve the first class $\mathrm{V}$ seizure compared with the untreated control group, which required 17.2 \pm 1.8 ADs (Table 2) $(p=0.012)$. The impairment of kindling progression could not be attributed to suppression of $\mathrm{AD}$ by an antiseizure effect of MK801, because there was no difference in the AD thresholds (Table 1), and the mean cumulative $\mathrm{AD}$ duration was greater in the pretreated groups than in the controls (Table 2).

It was of interest to determine whether MK801 had an effect on the progression of kindling during later stages of the kindling process. In the group pretreated with MK801 beginning after the first class $\mathrm{V}$ seizure, $35.7 \pm 1.9$ ADs were required to develop 10 class $\mathrm{V}$ seizures, whereas the untreated control group required only $29.3 \pm 1.6$ ADs (Table 2$)(p=0.024)$. The untreated control group required fewer ADs than the pretreated group to advance from the stage of 1 to 10 class $V$ seizures $(12.5 \pm 0.7$ vs $20.9 \pm 1.2$ ADs, $p=0.00004)$. Before the initiation of MK801 treatment, there was no significant difference between these groups in the number of ADs required to achieve one class V seizure (14.8 \pm 2.0 vs $17.5 \pm 1.1$ ADs, not significant) and no effect of MK801 on AD threshold (Table 1). MK801 pretreatment impaired the progression of kindling from 1 to 10 class $\mathrm{V}$ seizures despite significantly longer mean cumulative $\mathrm{AD}$ duration than the untreated group (Table 2) $(p<0.00001)$. 


\begin{tabular}{|c|c|c|c|}
\hline $\begin{array}{l}\text { Experimental } \\
\text { group }\end{array}$ & $\mathrm{AD}^{*}$ & $\begin{array}{l}\text { Cumulative AD } \\
\text { duration }(\mathrm{sec})^{*}\end{array}$ & Timm score* \\
\hline $\begin{array}{l}\text { Normal control } \\
\quad(n=7)\end{array}$ & - & - & $0.8 \pm 0.13$ \\
\hline $\begin{array}{l}\text { Kindling } \\
\qquad \begin{array}{l}1 \mathrm{Cl} \mathrm{V} \\
(n=9)\end{array}\end{array}$ & $17.2 \pm 1.8$ & $624 \pm 54$ & $3.44 \pm 0.29$ \\
\hline $\begin{array}{l}\text { MK801 } \\
\qquad \begin{array}{l}0-17 \text { ADs } \\
(n=7)\end{array}\end{array}$ & 17 & $840 \pm 58^{a}$ & $2.43 \pm 0.32^{b}$ \\
\hline $\begin{array}{l}\text { MK801 } \\
\qquad \begin{array}{l}10 \mathrm{AD}-1 \mathrm{Cl} \mathrm{V} \\
(n=9)\end{array}\end{array}$ & $24.2 \pm 1.7$ & $1166 \pm 110^{c}$ & $3.39 \pm 0.22$ \\
\hline $\begin{array}{l}\text { Kindling } \\
\qquad \begin{array}{l}10 \mathrm{Cl} \mathrm{V} \\
(n=8)\end{array}\end{array}$ & $29.3 \pm 1.6$ & $1451 \pm 83$ & $3.54 \pm 0.3$ \\
\hline $\begin{array}{l}\text { MK801 } \\
\qquad \begin{array}{l}1-10 \mathrm{Cl} \mathrm{V} \\
(n=9)\end{array}\end{array}$ & $35.7 \pm 1.9$ & $2066 \pm 48^{d}$ & $3.29 \pm 0.27$ \\
\hline \multicolumn{4}{|c|}{$\begin{array}{l}{ }^{*} p<0.0001, \text { ANOVA. } \\
{ }^{a} \text { versus kindling } 1 \mathrm{Cl} \mathrm{V}, p<0.017 . \\
{ }^{b} \text { versus kindling } 1 \mathrm{Cl} \mathrm{V}, p<0.032 . \\
{ }^{c} \text { versus kindling } 1 \mathrm{Cl} \mathrm{V}, p<0.001 . \\
{ }^{d} \text { versus kindling } 10 \mathrm{Cl} \mathrm{V}, p<0.00001 .\end{array}$} \\
\hline
\end{tabular}

\section{Effects of MK801 on mossy fiber sprouting}

In agreement with previous studies, kindling induced development of Timm granules, which correspond to mossy fiber synaptic terminals, in the supragranular region of the DG (Sutula et al., 1988; Cavazos et al., 1991). Pretreatment with MK801, which slowed the progression of kindling, also induced a corresponding impairment in the development of the mossy fiber sprouting, as assessed by the scoring methods for Timm histochemistry.

The development of sprouting was impaired in the group that received MK801 beginning with the initial stimulation (Table 2) $(p<0.0001$, ANOVA). In the saline-injected control group that experienced the first evoked class V seizure after a mean of $17.2 \pm$ 1.8 ADs, the mean Timm score was $3.44 \pm 0.29$. After 17 ADs, the MK801-pretreated group only reached the behavioral stage of class III, and the mean Timm score was significantly lower $(2.43 \pm$ $0.32, p<0.032$ ) (compare Fig. $3 B$ and $3 C$ ). In the pretreated group that experienced nearly identical numbers of evoked ADs and had a longer cumulative $\mathrm{AD}$ duration than the saline-injected control group, MK801 impaired both the progression of kindling and the development of mossy fiber sprouting.

In the group that was pretreated with MK801 beginning after the 10th $\mathrm{AD}$ and continuing to the first class V seizure, the mean Timm score was $3.39 \pm 0.22$, which was not significantly different from the Timm score of the saline-injected control group that experienced one class V seizure. Although the MK801-treated group experienced more ADs and had a longer mean cumulative $\mathrm{AD}$ duration than the control group, the sprouting was comparable in these groups at the stage of one class V seizure (Table 2) (compare Fig. $3 B$ and $3 D$ ).

Similarly, in the group that was pretreated with MK801 beginning after the first and continuing to the 10th class V seizure, the mean Timm score was not significantly different from the Timm score of the saline-injected control group that experienced 10 class V seizures. Although the MK801-treated group experienced more $\mathrm{ADs}$ and had a longer mean cumulative $\mathrm{AD}$ duration than the control group, the sprouting was also comparable in these groups at the stage of 10 class $\mathrm{V}$ seizures (Table 2) (compare Fig. $4 A$ and $4 B)$.

\section{DISCUSSION}

In this study, in vivo administration of the NMDA receptor antagonist MK801 in doses that had minimal or no antiseizure effect impaired the initial development of kindling, impaired the continuing progression of kindling in response to repeated stimulation in fully kindled animals, and concomitantly impaired seizure-induced mossy fiber sprouting. These observations implicated the NMDA receptor as a pivotal component of a signaling cascade that translates the initial transmembrane alterations induced by kindling stimulation into long-term alterations of neuronal structure and function in the DG.

\section{The NMDA receptor dependence of kindling progression}

In previous studies, low doses of MK801 impaired the early phase of kindling development but did not have anticonvulsant effects against evoked class $\mathrm{V}$ seizures in fully kindled rats (McNamara et al., 1988; Sato et al., 1988; Löscher and Hönack, 1991). In this study, doses of the maleate salt of MK801 in the range of 0.5 $\mathrm{mg} / \mathrm{kg}$ also had no antiseizure effect against class V seizures and were not sufficient to prevent ADs in response to a standardized stimulation protocol. This dose, however, delayed but did not prevent the development of class $\mathrm{V}$ seizures in response to repeated stimulation and also impaired the rate of progression to more advanced stages of kindling. These observations implicate the NMDA receptor in the progression of kindling.

The low dose of MK801 used in these experiments increased the stimulus strength required to evoke an $\mathrm{AD}$ but only during the initial stage of the kindling process. This observation is consistent with the view that the NMDA receptor plays a role in the induction of kindling in response to perforant path stimulation. In normal rats, a substantial component of the perforant pathevoked EPSP in granule cells of the DG is NMDA-dependent (Lambert and Jones, 1991). The low dose of MK801 increased the initial AD threshold, perhaps by blocking NMDA-dependent synaptic input that contributes to synchronization and the epileptiform AD. Higher stimulation intensities were sufficient to overcome the effects of MK801 and also evoked ADs, but kindling still failed to progress at a normal rate toward class V seizures despite the higher stimulus intensities, repeated ADs, and greater cumulative evoked seizure activity.

In later stages of kindling, pretreatment with MK801 also impaired the rate of progression to more advanced behavioral stages. An antiseizure effect of MK801 is unlikely, because the low dose of MK801 was accompanied by prolonged ADs and increased cumulative electrographic seizure activity, as reported previously (Gilbert and Mack, 1990; Gilbert, 1991). The mechanisms by which MK801 prolongs AD duration are not clear, but in previous studies, MK801 has increased the number of action potentials generated by granule cells (Labiner et al., 1993), perhaps by reducing $\mathrm{Ca}^{2+}$ influx through NMDA channels, which would be expected to reduce spike adaptation by reducing $\mathrm{Ca}^{2+}$ dependent $\mathrm{K}^{+}$conductances. 

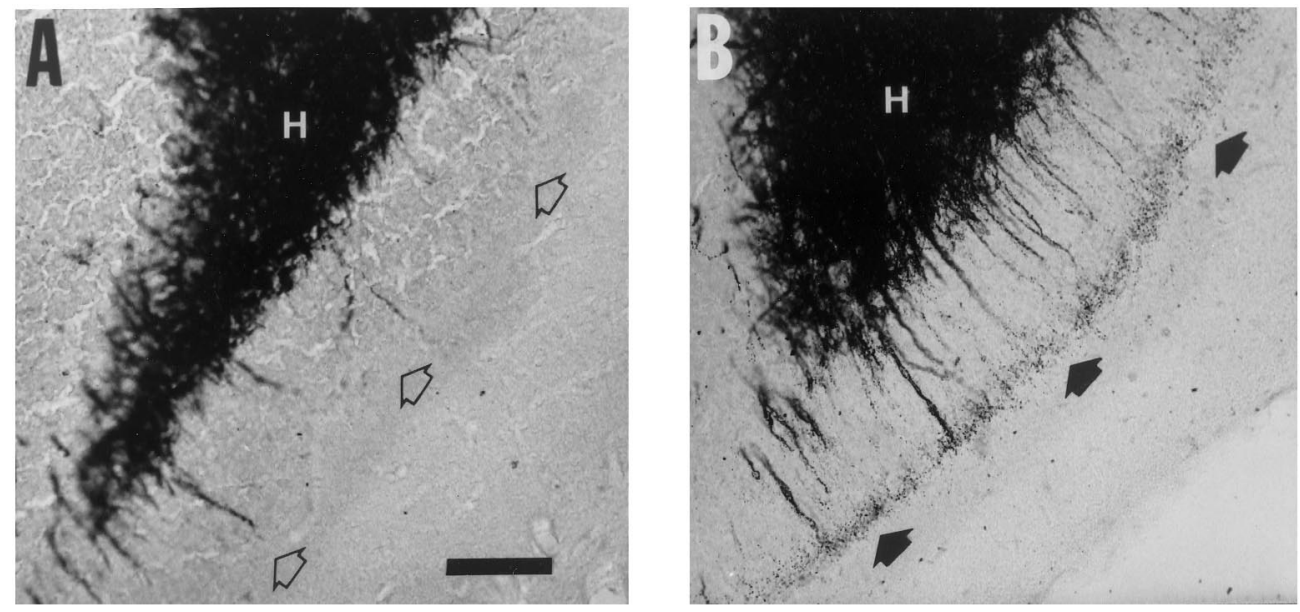

Figure 3. Higher-magnification views of horizontal Timm-stained sections in the standard location in the DG described in Figure 1. $A$, Higher magnification of the boxed area in Figure 1 demonstrates the appearance of the supragranular area of the DG from a normal rat, which is not innervated by mossy fiber axons and has few or no dark staining granules (open arrows). $B$, Higher magnification of the same region in a kindled rat that received once-daily stimulation that evoked 14 afterdischarges and 1 class $\mathrm{V}$ secondary generalized tonic-clonic seizure. The supragranular region contains numerous dark Timm granules corresponding to synapses of mossy fiber axons, which form a laminar band (filled
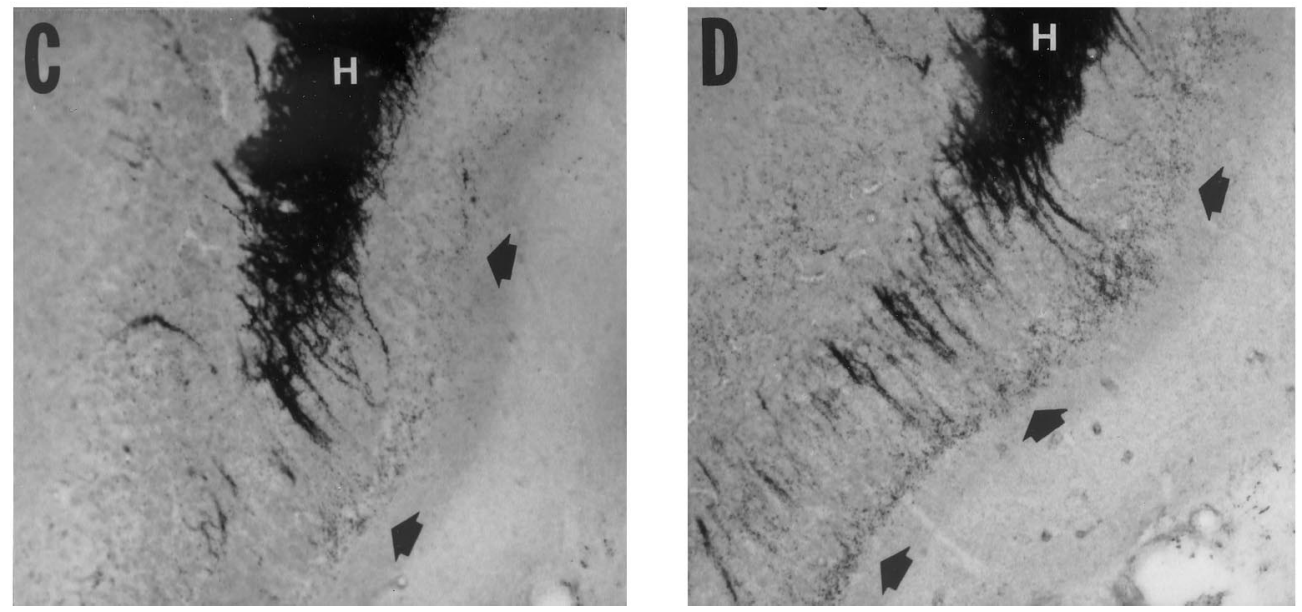
arrows). $C$, Higher magnification from the same region in a rat that received MK801 before each stimulation until 17 afterdischarges were evoked. Timm granules are present in the supragranular layer (filled arrows) but are not as prominent as in the untreated rat in $B$. $D$, Higher magnification from the same region in a rat that received MK801 before each stimulation beginning after the 10th afterdischarge and continuing until 1 class V seizure was evoked. The supragranular region contains numerous dark Timm granules that form a laminar band (filled arrows). Untreated rats that experienced 1 class $V$ seizure had comparable mossy fiber synaptic reorganization, as assessed by Timm scores (see Table 2). $H$, Hilus. Scale bar (shown in $A$ ): $100 \mu \mathrm{m}$.

\section{The NMDA receptor dependence of mossy fiber sprouting: association with the progression of kindling}

Blockade of the NMDA receptors not only impaired the progression of kindling but also impaired induction of mossy fiber sprouting in response to repeated evoked seizures. The effects of NMDA receptor antagonism on kindling progression and mossy fiber synaptic reorganization are summarized in Figure 5. In the group that was pretreated with MK801 from the initial stimulation until 17 ADs, synaptic reorganization of the mossy fiber pathway was reduced compared with the control group that experienced an equivalent number of ADs. These results suggest that MK801 caused a dissociation between induction of ADs and mossy fiber sprouting despite the overall greater cumulative $\mathrm{AD}$ duration in the treated group. The groups pretreated with MK801 at later stages of kindling also experienced more ADs, longer individual ADs, and more cumulative seizure activity than controls, but the extent of mossy fiber synaptic reorganization was comparable at the same behavioral stage of kindling. In groups treated with MK801 during both the initial and more advanced stages of kindling, longer periods of evoked seizure activity were required
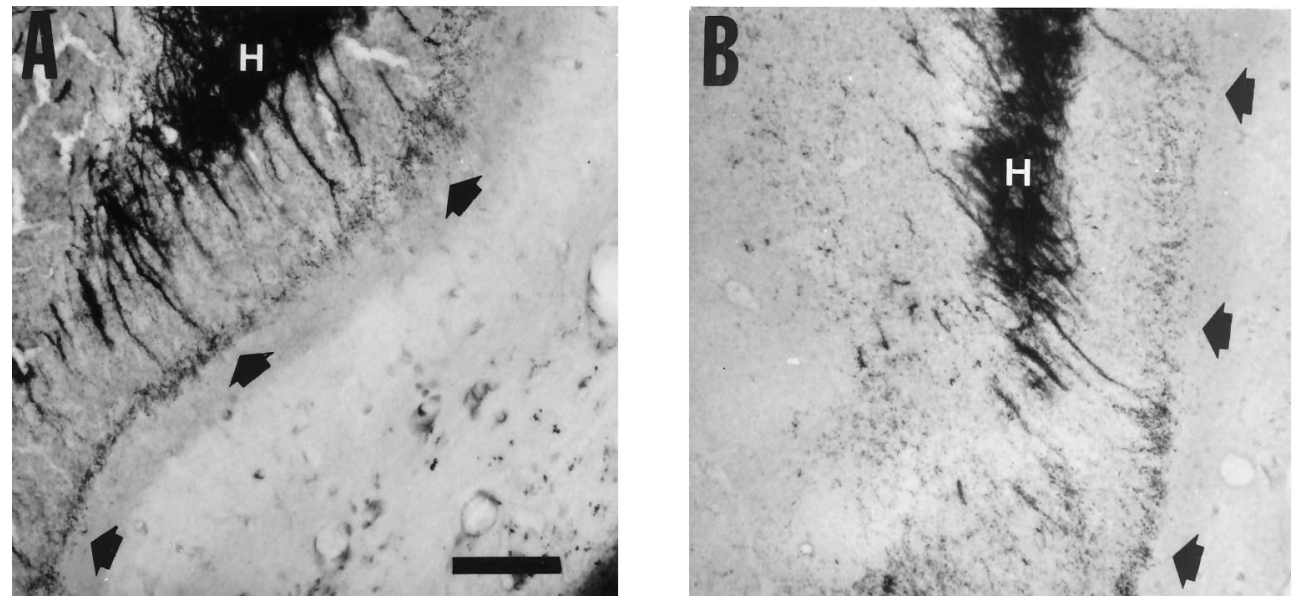

Figure 4. A, Higher magnification of the DG in a kindled rat that received once-daily stimulation that evoked 25 afterdischarges and 10 class $\mathrm{V}$ secondary generalized tonic-clonic seizures. The supragranular region contains numerous dark Timm granules corresponding to synapses of mossy fiber axons, which form a laminar band (filled arrows). B, Higher magnification from the same region in a rat that received MK801 before each stimulation after the first class $V$ seizure and continuing until 10 class $\mathrm{V}$ seizures were evoked. This rat required 34 afterdischarges to evoke 10 class $\mathrm{V}$ seizures. The supragranular region also contains a laminar band of Timm granules (filled arrows). $H$, Hilus. Scale bar (shown in $A$ ): $100 \mu \mathrm{m}$. 
Figure 5. Summary of the effects of MK801 on the kindling rate and mossy fiber synaptic reorganization for groups of control rats and rats treated with MK801. The kindling rate was expressed as the mean number of afterdischarges, and mossy fiber synaptic reorganization was assessed by mean Timm scores. The error bars indicate the SEM for each group; *, versus Timm score for CONTROL $1 C L V, p=0.032$; **, versus kindling rate for CONTROL $1 C L V$, $p=0.012 ; * *$, versus kindling rate for $C O N$ -

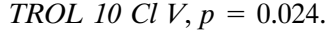

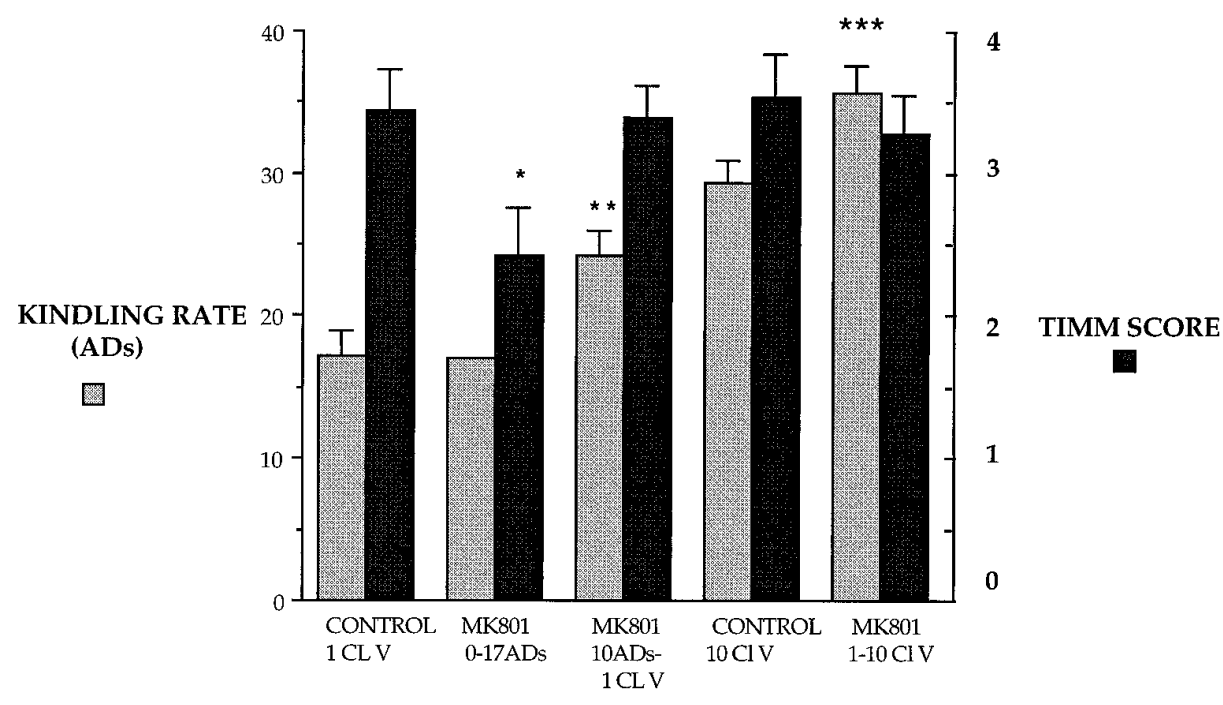

to induce equivalent progression of kindling and comparable synaptic reorganization.

There was a close association between the extent of mossy fiber synaptic reorganization and the behavioral stage of kindling. Kindled rats at the stages of 1 and 10 class $\mathrm{V}$ seizures demonstrated comparable synaptic reorganization of the mossy fiber pathway, regardless of the number of ADs or duration of seizure activity required to achieve that stage of kindling. This observation supports the view that mossy fiber sprouting is a cellular alteration that is closely correlated with the kindled state and may contribute to long-term susceptibility to seizures and epilepsy.

This study does not address the possible cellular and molecular mechanisms that underlie the effect of NMDA receptor blockade on kindling progression and mossy fiber sprouting. In particular, it is unclear whether MK801 also reduced seizure-induced neuronal loss, which would be expected to reduce sprouting, or whether a component of seizure-induced sprouting may be dependent on neural activity in the absence of neuronal loss, as suggested by recent studies in mice carrying a null mutation for c-fos (Watanabe et al., 1996). Kindling to advanced stages eventually induces neuronal loss in the hippocampus (Cavazos and Sutula, 1990; Cavazos et al., 1994), which is correlated with repeated class $\mathrm{V}$ seizures. The pattern of seizure-induced neuronal loss in the hilus of the DG, CA1, and CA3 resembles hippocampal sclerosis (Cavazos et al., 1994), the most common lesion in human epilepsy (Gloor, 1991).

\section{The NMDA receptor as a component of the signaling cascade that regulates seizure-induced mossy fiber sprouting}

Pretreatment with MK801 decoupled evoked electrographic seizure activity from the progression of kindling and the associated seizure-induced cellular alteration of mossy fiber sprouting. Although it is clearly necessary to evoke repeated ADs to induce kindling (Goddard et al., 1969; Racine et al., 1972), blockade of NMDA receptors during synchronous epileptiform discharges impaired the development of mossy fiber sprouting and possibly other unrecognized cellular alterations that contributed to the long-term susceptibility to evoked and spontaneous seizures that characterize the kindled state.

In a previous study, administration of phenobarbital, which suppressed seizures induced by the glutamate analog kainic acid in rats, also reduced seizure-induced neuronal damage and mossy fiber sprouting in the DG and abolished the increased susceptibility to kindling that follows treatment with kainic acid (Sutula et al., 1992). That study demonstrated that pharmacological suppression of seizures can modify long-term seizure-induced cellular alterations that may play a role in the development of epilepsy. In this study with MK801 in the kindling model, pharmacological blockade of NMDA receptors during repeated electrographic seizure activity also modified the induction of mossy fiber sprouting and long-term effects of seizures without suppression of seizures. The effect was observed during the initial and more advanced stages of the kindling process and is consistent with the possibility that repeated or sustained activation of the NMDA receptor during seizures sets into motion a signaling cascade that leads to long-term alterations of neuronal structure and function.

The NMDA receptor activates distinct, independently regulated intracellular signaling pathways (Lerea et al., 1992). The results of this study are consistent with the possibility that NMDA-dependent gene expression induced by repeated seizures contributes to the long-term modification of neuronal structure and function that characterizes the kindled state. Of particular interest is the implication of a potentially specific role of the NMDA receptors (Dürnmüller et al., 1994) in the generation of long-term seizure-induced functional and structural cellular alterations such as sprouting. The effects of NMDA receptor blockade on both kindling progression and sprouting during early and later stages of kindling suggest that the NMDA receptor contributes to activity-dependent, long-term modification of neuronal structure and function throughout the kindling process. Although there is substantial direct evidence that the NMDA receptor regulates patterning of neural circuitry in development (Cline and Constantine-Paton, 1990; Shatz, 1990) and plays a role in activitydependent plasticity such as long-term potentiation in the adult brain, it has not been clear that the NMDA receptor continues to influence patterning of circuitry in the adult nervous system. The results of this study provide evidence that the NMDA receptor continues to regulate formation and patterning of connections formed by reactive synaptogenesis in the adult nervous system.

The repeated brief seizures evoked by kindling, which resemble human partial complex seizures and induce epilepsy, also induce memory deficits that are similar to the memory dysfunction observed in human epilepsy (Sutula et al., 1995). The effectiveness of MK801 in preventing long-term, potentially deleterious modifica- 
tion of neural circuitry by seizures suggests the possibility for development of pharmacological treatment to prevent long-term effects of repeated or intense seizures, which include development of medically intractable epilepsy and memory disorders.

\section{REFERENCES}

Bendotti C, Vezzani A, Tarizzo G, Samanin R (1993) Increased expression of GAP-43, somatostatin and neuropeptide Y mRNA in the hippocampus during development of hippocampal kindling in rats. Eur J Neurosci 5:1312-1320.

Bengzon J, Kokaia Z, Ernfors P, Kokaia M, Leanza G, Nilsson O, Persson H, Lindvall O (1993) Regulation of neurotrophin and trkA and trkC tyrosine kinase receptor messenger RNA expression in kindling. Neuroscience 53:433-436.

Bowyer J, Albertson T, Winters W, Baselt R (1983) Ketamine induced changes in kindled amygdaloid seizures. Neuropharmacology 22:887-894.

Bugra K, Pollard H, Charton G, Moreau J, Ben Ari Y, Khrestchatisky M (1994) aFGF, bFGF, and flg mRNAs show distinct patterns of induction in the hippocampus following kainate-induced seizures. Eur J Neurosci 6:58-66.

Buhl E, Otis T, Mody I (1996) Zinc induced collapse of augmented inhibition by GABA in temporal lobe epilepsy model. Science 271:369-373.

Callahan D, Schwark W (1980) Pharmacological modification of amygdaloid-kindled seizures. Neuropharmacology 19:1131-1136.

Cavazos J, Sutula T (1990) Progressive neuronal loss induced by kindling: a possible mechanism for mossy fiber synaptic reorganization and hippocampal sclerosis. Brain Res 527:1-6.

Cavazos J, Golarai G, Sutula T (1991) Mossy fiber synaptic reorganization induced by kindling: time course of development, progression, and permanence. J Neurosci 11:2795-2803.

Cavazos J, Golarai G, Sutula T (1992) Septotemporal variation of the supragranular projection of the mossy fiber pathway in the dentate gyrus of normal and kindled rats. Hippocampus 2:363-372.

Cavazos J, Das I, Sutula T (1994) Neuronal loss induced in limbic pathways by kindling: evidence for induction of hippocampal sclerosis by brief repeated seizures. J Neurosci 14:3106-3121.

Claiborne BJ, Amaral D, Cowan W (1986) A light and electron microscopic analysis of the mossy fibers of the rat dentate gyrus. J Comp Neurol 246:435-458.

Cline H, Constantine-Paton M (1990) NMDA receptor agonists and antagonists alter retinal ganglion cell arbor structure in the developing frog retinotectal projection. J Neurosci 10:1197-1216.

Cronin H, Obenhaus A, Houser C, Dudek FE (1992) Electrophysiology of dentate granule cells after kainate-induced synaptic reorganization of mossy fibers. Brain Res 573:305-310.

Danscher G, Howell G, Perez-Clausell J, Hertel N (1985) The dithizone, Timm's sulphide silver and the selenium methods demonstrate a chelatable pool of zinc in CNS. Histochemistry 83:419-422.

de Lanerolle N, Kim J, Robbins R, Spencer D (1989) Hippocampal interneuron loss and plasticity in human temporal lobe epilepsy. Brain Res 495:387-395.

Dragunow M, Robertson H (1987) Kindling stimulation induces c-fos protein in granule cells of the rat DG. Nature 329:441-442.

Dürnmüller N, Craggs M, Meldrum BS (1994) The effect of non-NMDA receptor antagonists GYKI 52466 and NBQX, and the competitive NMDA receptor antagonist d-CPP on the development of amygdala kindling and on amygdala kindled seizures. Epilepsy Res 17:167-174.

Ernfors P, Bengzon J, Kokaia Z, Persson H, Lindvall O (1991) Increased levels of messenger RNAs for neurotrophic factors in the brain during kindling epileptogenesis. Neuron 7:165-176.

Frush D, Giacchino J, McNamara JO (1986) Evidence implicating dentate granule cells in development of entorhinal kindling. Exp Neurol 92:92-101.

Gall C (1993) Seizure-induced changes in neurotrophin expression: implications for epilepsy. Exp Neurol 124:150-166.

Gall C, Isackson P (1989) Limbic seizures increase neuronal production of messenger RNA for nerve growth factor. Science 245:758-761.

Gilbert M (1991) Potentiation of inhibition with perforant path kindling: an NMDA receptor dependent process. Brain Res 564:109-116.

Gilbert M, Mack C (1990) The NMDA antagonist MK-801 suppresses long-term potentiation, kindling, and kindling-induced potentiation in the perforant path of the unanesthetized rat. Brain Res 519:89-96.
Giorgi O, Orlandi M, Lecca D, Corda M (1991) MK-801 prevents chemical kindling induced by pentylenetetrazol in rats. Eur J Pharmacol 193:363-365.

Gloor P (1991) Mesial temporal sclerosis: historical background and an overview from a modern prospective. In: Epilepsy surgery (Luders H, ed), pp 689-703. New York: Raven.

Goddard G, McIntyre D, Leech C (1969) A permanent change in brain function resulting from daily electrical stimulation. Exp Neurol 25:295-330.

Golarai G, Sutula T (1996) Functional alterations in the dentate gyrus after induction of long-term potentiation, kindling, and mossy fiber sprouting. J Neurophysiol 75:343-353.

Golarai G, Cavazos J, Sutula T (1992) Activation of dentate gyrus by pentylenetetrazol evoked seizures induces mossy fiber synaptic reorganization. Brain Res 593:257-264.

Hope B, Kelz M, Duman R, Nestler E (1994) Chronic electroconvulsive seizure (ECS) treatment results in expression of a long-lasting AP-1 complex in brain with altered composition and characteristics. J Neurosci 14:4318-4328

Hosford D, Simonato M, Cao Z, Garcia-Cairasco N, Silver J, Butler L, Shin C, McNamara JO (1995) Differences in the anatomic distribution of immediate early gene expression in the amygdala and angular bundle kindling development. J Neurosci 15:2513-2523.

Houser C, Miyashiro J, Swartz B, Walsh G, Rich J, Delgado-Escueta AV (1990) Altered patterns of dynorphin immunoreactivity suggest mossy fiber reorganization in human hippocampal epilepsy. J Neurosci 10:276-282.

Khrestchatisky M, Ferhat L, Charton G, Bernard A, Pollard H, Represa A, Ben-Ari Y (1995) Molecular correlates between reactive and developmental plasticity in the rat hippocampus. J Neurobiol 26:426-436.

Koch J, Golarai G, Watanabe Y, McNamara JO, Sutula T (1994) Antiepileptogenic effect of the NMDA antagonist MK-801 on the progression of kindling and mossy fiber sprouting. Epilepsia 35:85.

Labiner D, Butler L, Cao Z, Hosford D, Shin C, McNamara JO (1993) Induction of c-fos mRNA by kindled seizures: complex relationship with neuronal burst firing. J Neurosci 13:744-751.

Lambert J, Jones R (1991) A reevaluation of excitatory amino acidmediated synaptic transmission in rat DG. J Neurophysiol 64:119-132.

Lerea L, Butler L, McNamara JO (1992) NMDA and non-NMDA receptor mediated increase in c-fos mRNA in DG. J Neurosci 12:2973-2981.

Lindvall O, Kokaia Z, Bengzon J, Elmer E, Kokaia M (1994) Neurotrophins and and brain insults. Trends Neurosci 17:490-496.

Lodge D, Johnson K (1990) Noncompetitive excitatory amino acid antagonists. Trends Pharmacol Sci 11:81-86.

Löscher W, Hönack D (1991) Anticonvulsant and behavioral effects of two novel competitive $N$-methyl-D-aspartic acid receptor antagonists, CGP 37849 and cCGP 39551, in the kindling model of epilepsy. Comparison with MK-801 and carbamazepine. J Pharmacol Exp Ther 256:432-440.

McNamara JO (1994) Cellular and molecular basis of epilepsy. J Neurosci 14:3413-3425.

McNamara JO, Russell R, Rigsbee L, Bonhaus D (1988) Anticonvulsant and antiepileptogenic actions of MK-801 in the kindling and electroshock models. Neuropharmacology 94:563-568.

Meberg P, Gall C, Routtenberg A (1993) Induction of F1/GAP-43 gene expression in hippocampal granule cells after seizures. Mol Brain Res 17:295-297.

Mody I, Heinemann U (1987) $N$-methyl-D-aspartate (NMDA) receptors of dentate gyrus granule cells participate in synaptic transmission following kindling. Nature 326:701-704.

Mody I, Stanton P, Heinemann U (1988) Activation of $N$-methyl-Daspartate receptors parallels changes in cellular and synaptic properties of dentate gyrus cells after kindling. J Neurophysiol 59:1033-1054.

Morgan J, Curran T (1991) Stimulus-transcription coupling in the nervous system: involvement of the inducible proto-oncogenes fos and jun. Annu Rev Neurosci 14:421-451.

Qiao X, Noebels J (1993) Developmental analysis of hippocampal mossy fiber outgrowth in a mutant mouse with inherited spike-wave seizures. J Neurosci 13:4622-4635.

Racine R (1972) Modification of seizure activity by electrical stimulation. II. Motor seizure. Electroencephalogr Clin Neurophysiol 32:281-294.

Represa A, le Gall la Salle G, Ben-Ari Y (1989a) Hippocampal plasticity in the kindling model of epilepsy in rats. Neurosci Lett 99:345-350. 
Represa A, Robain O, Tremblay E, Ben-Ari Y (1989b) Hippocampal plasticity in childhood epilepsy. Neurosci Lett 99:351-355.

Sato K, Morimoto K, Okamoto M (1988) Anticonvulsant action of a non-competitive antagonist of NMDA receptors (MK-801) in the kindling model of epilepsy. Brain Res 463:12-20.

Shatz C (1990) Impulse activity and the patterning of connections during CNS development. Neuron 5:745-756.

Shin C, McNamara JO, Morgan J, Curran T, Cohen D (1990) Induction of c-fos mRNA expression by afterdischarge in the hippocampus of naive and kindled rats. J Neurochem 55:1050-1055.

Sloviter R (1992) Possible functional consequences of synaptic reorganization in the dentate gyrus of kainate treated rats. Neurosci Lett 137:91-96.

Stanfield B (1989) Excessive intra- and supra-granular mossy fibers in the dentate gyrus of tottering ( $\mathrm{tg} / \mathrm{tg}$ ) mice. Brain Res 480:294-299.

Sutula T, Steward O (1986) Quantitative analysis of synaptic potentiation during kindling of the perforant path. J Neurophysiol 56:732-745.

Sutula T, Harrison C, Steward O (1986) Chronic epileptogenesis induced by kindling of the entorhinal cortex: the role of the DG. Brain Res 385:291-299.

Sutula T, He XX, Cavazos J, Scott G (1988) Synaptic reorganization in the hippocampus induced by abnormal functional activity. Science 239:1147-1150.

Sutula T, Cascino G, Cavazos J, Parada I, Ramirez L (1989) Mossy fiber synaptic reorganization in the epileptic human temporal lobe. Ann Neurol 26:321-330.

Sutula T, Cavazos J, Golarai G (1992) Alteration of long-lasting structural and functional effects of kainic acid in the hippocampus by brief treatment with phenobarbital. J Neurosci 12:4173-4187.

Sutula T, Lauersdorf S, Lynch M, Jurgella C, Woodard A (1995) Deficits in radial arm maze performance in kindled rats: evidence for longlasting memory dysfunction induced by repeated brief seizures. J Neurosci 15:8295-8301.

Tauck D, Nadler JV (1985) Evidence of functional mossy fiber sprouting in hippocampal formation of kainic acid treated rats. J Neurosci 5:1016-1022.

Watanabe Y, Johnson R, Butler L, Binder D, Spiegelman Papaioannou V, McNamara JO (1996) Null mutation of c-fos impairs structural and functional plasticities in the kindling model of epilepsy. J Neurosci 16:3827-3836.

Waurin JP, Dudek FE (1996) Electrographic seizures and new recurrent excitatory circuits in the dentate gyrus of hippocampal slices from kainate-treated epileptic rats. J Neurosci 16:4438-4448. 